\title{
Parental RNAi Silencing of the transformer-2 Gene in a Species of the Anastrepha fraterculus Complex of Cryptic Species (Diptera, Tephritidae)
}

\author{
Pietro E. Vicari ${ }^{1}$, Esther S. Chang ${ }^{1}$, André L. P. Perondini ${ }^{1} \&$ Denise Selivon ${ }^{1}$ \\ ${ }^{1}$ Department of Genetics and Evolutionary Biology, Institute of Biosciences, University of São Paulo, São Paulo, \\ Brazil \\ Correspondence: Pietro E. Vicari, Department of Genetics and Evolutionary Biology, Institute of Biosciences, \\ University of São Paulo, São Paulo, Brazil. Tel: 55-11-3091-7551. E-mail: pietro.vento@usp.br
}

Received: June 13, 2021

Accepted: August 20, $2021 \quad$ Online Published: September 15, 2021

doi:10.5539/jas.v13n10p70

URL: https://doi.org/10.5539/jas.v13n10p70

\begin{abstract}
In genera Anastrepha, Bactrocera and Ceratitis of the tephritid fruit flies the auto-regulatory function of gene transformer is assumed to be activated by maternal derived mRNA or the proteins of the gene transformer (tra-2 $\left.{ }^{m a t}\right)$ and transformer-2 $\left(\right.$ tra- $\left.2^{\text {mat }}\right)$. However, this maternal effect was not yet been demonstrated. The objective of the present study was to test the effect of absence of tra- $2^{\text {mat }}$ in the eggs on the sex determination of $A$. sp.1 affinis fraterculus. This was achieved by silencing gene tra-2 in the parental females via the pRNA interference. The data showed that tra-2 was transiently silenced in the female for three weeks period. The progenies sex ratio produced by these females during the silencing of tra-2 depart from 1:1 in favor of males. The excess of males was due to the transformation of a fraction of genotypical female XX embryos into XX males, the so-called pseudomales, Individual F1 males from the offspring of treated females crossed to females from the stock, revealed that majority of them showed regular mating behavior and were fertile. However, no offspring was produced in the crosses by a fraction of males that have produced sperms, showed regular mating behavior but did not transfer sperms to the females. The data allow the conclusion that the absence of $t r a-2^{\text {mat }}$ in the eggs had impaired the self-regulation of the embryonic gene tra resulting in the transformation of XX embryos into pseudomales and also that these pseudomales are sterile. This effect may be useful improve more sustainable technologies for fruit fly control such as SIT.
\end{abstract}

Keywords: sex determining, pRNAi, Anastrepha, transformer-2, pseudomales

\section{Introduction}

Some fruit fly species of the Tephritidae family are considered one of the most devasting insect pests of agriculture The species of economic and quarantine importance (ca.78 species) damage the horticulture industry worldwide, reaching losses of billions of US dollars every year (Rendón \& Enkerlin, 2021). The most important genera include Anastrepha (Schiner) indigenous to the Americas, Bactrocera (Macquart) in Asia and Oceania, Dacus (Fabricius) in Africa, Rhagoletis (Loew) in more temperate areas of Europe, North and South America, and the Zeugodacus (Hendel) in Asia (White \& Elson-Harris, 1992; Rendón \& Enkerlin, 2021).

The genus Anastrepha is endemic to the American tropics and subtropics, and many of its pest species have a wide distribution within this range (Norrbom \& Foote, 1989). The South American fruit fly, Anastrepha fraterculus (Wiedemann) is a complex of cryptic species that has a wide geographic distribution almost the same as the genus and uses many host plants for larval development (Zucchi \& Moraes, 2008; Norrbom et al., 2013). This species involves a complex of cryptic species, the so-called Anastrepha fraterculus complex of cryptic species that is being currently characterized (Selivon et al., 2004, 2005; Hernández-Ortiz et al., 2012, 2015; Hendrichs et al., 2015; Vaníčková et al., 2015; Prezotto et al., 2019). Due to the economic importance of the Anastrepha species programmes for their control, SIT for example, have been established in several countries along the continent (Rendón \& Enkerlin, 2021). However, the effectiveness of such programs can in some cases be increased with the establishment of so-called sexing system to eliminate females allowing male-only releases. Therefore, new strategies to improve the massive production of males in the biofabrics are ever since being pursued, one of which is based on the knowledge of the genetic/molecular mechanism of sex determination of 
the targeted species in search of gene alteration that cause sex ratio modification in favor of males (Häcker \& Schetelig, 2021).

Sex determination in insects is achieved by a variety of mechanism but are commonly based on a hierarchic cascade of genes, the product of one gene controlling the sex-specific splicing of the pre-mRNA of the gene downstream in the hierarchy. It has been demonstrated that sex determination in frugivorous Tephritidae flies is controlled by the activity of a set of three key genes, transformer (tra), transformer-2 (tra-2) and doublesex (dsx). Differentially from Drosophila, in which gene Sexlethal ( $S x l$ ) is on the top of gene cascade of sex determination, in tephritid flies and other dipteran insects it does not have this function (Belote et al., 1989, Saccone et al., 1998, Saccone et al., 2002; Sánchez, 2008; Hediger et al., 2010; Verhulst et al., 2010; Gempe \& Beye, 2011; Bopp et al., 2014; Bachtrog et al., 2014). In tephritids, gene tra is expressed in both sexes but produces functional Tra protein only in females by a self-regulatory mechanism that is imposed by the maternal $\operatorname{tra}\left(\operatorname{tra}^{m a t}\right)$ and $\operatorname{tra}-2$ $\left(t_{r a} 2^{m a t}\right)$ RNA or their proteins deposited in the eggs (Pane et al., 2002; Ruiz et al., 2007a, 2007b; Sarno et al., 2010; Luo et al., 2017) in conjunction with the embryonic transformer-2 gene (Salvemini et al., 2009). The functional Tra protein plus the constitutive embryonic Tra-2 protein control the female-specific splicing of the pre-mRNA of gene $d s x$, producing a female $\mathrm{Dsx}^{\mathrm{F}}$ protein. This protein acts controlling the expression of many cytodifferentiation genes, which results in the expression of female phenotype (Figure 1, left). The Y chromosome of the tephritid Ceratitis capitata carry a linked M factor that determines the male sex by repressing directly or indirectly the function of embryonic tra gene (Willhofet \& Franz, 1996; Pane et al., 2002). The molecular nature of the $\mathrm{M}$ factor of $C$. capitata and of four species of Bactrocera, was identified and the gene named as Maleness-on-the-Y (MoY) (Meccariello et al., 2019). This factor is being hypothesized to exists also in other genera of frugivorous tephritid flies (Sánchez, 2008). Thus, in males no functional Tra protein is produced and the splicing of $d s x$ displays its default form, giving rise to production of male specific protein Dsx $^{\mathrm{M}}$ which leads to development of male phenotype (Figure 1, right). The tephritid sex determination mechanism has been found in species of Bactrocera (Shearman \& Frommer, 1998; Lagos et al., 2005; Chen et al., 2008; Permpoon et al., 2011; Liu \& Wan, 2015; Liu et al., 2015; Morrow et al., 2014; Laohakieat et al., 2016; Luo et al., 2017), in Ceratitis capitata (Pane et al. 2007; Saccone et al., 2002, 2011; Salvemini et al., 2009) and in 12 species of Anastrepha (Ruiz et al., 2007a, 2007b; Sarno et al., 2010; Schetelig et al., 2012).
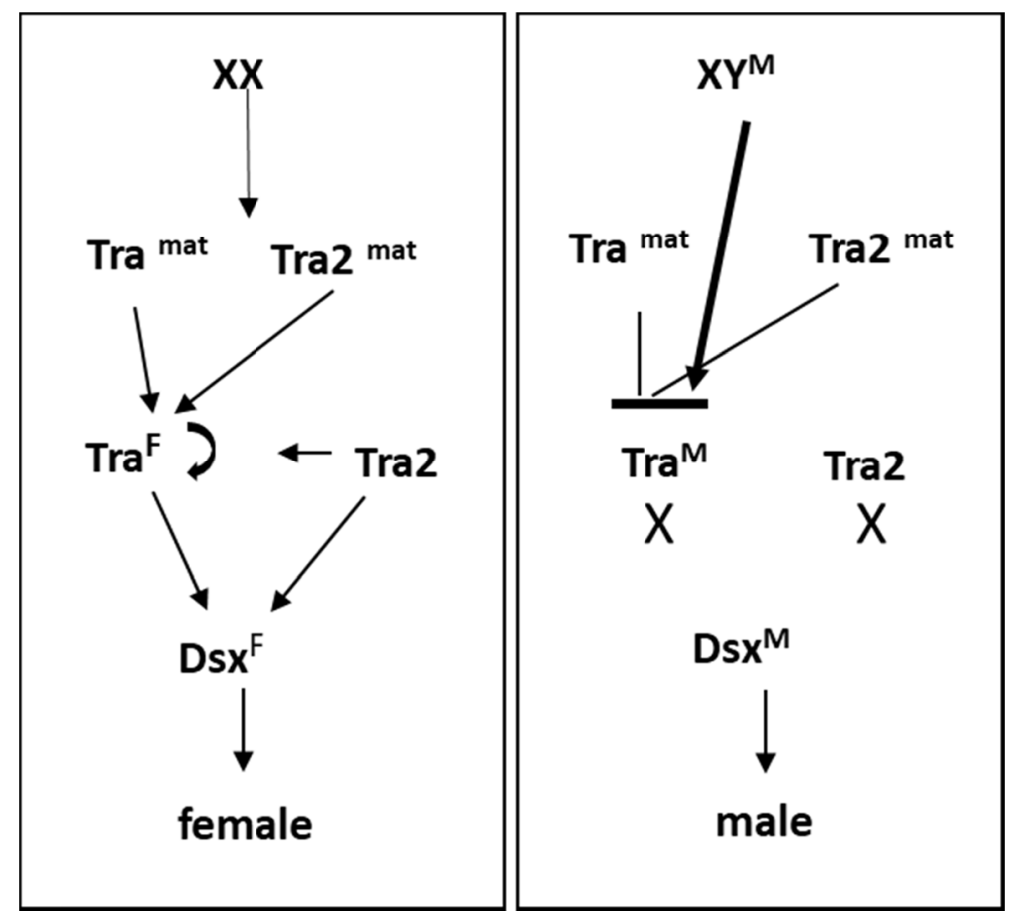

Figure 1. Sex determination cascade in Tephritidae flies. Tra ${ }^{\text {mat }}$ and Tra- $2^{\text {mat }}$ are maternal Tra and Tra-2 products. $\mathrm{Dsx}^{\mathrm{F}}$ and $\mathrm{Dsx}^{\mathrm{M}}$ stand for Dsx proteins. $\mathrm{Y}^{\mathrm{M}}$ is the putative $\mathrm{M}$ factor supposed to exists on the $\mathrm{Y}$ chromosome of Anastrepha species. Schemes redrawn based on Sánchez (2008) 
Experimentally, the role of the three genes in sex determination of tepritid species has been elucidated by the embryonic RNAi methodology. Injection of tradsRNA, of tra2dsRNA and/or dsxdsRNA, in the eggs of Ceratitis (Pane et al., 2002, 2007; Salvemini et al., 2009), Bactrocera (Chen et al., 2008; Liu et al., 2015; Peng et al., 2015), Anastrepha (Sarno et al., 2010; Schetelig et al., 2012) as well as of MoYdsRNA in C. capitata and species of Bactrocera (Meccariello et al., 2019), results in the male-specific splicing of pre-mRNA of tra and of $d s x$ in genotypic female embryos. This leads to transformation of a fraction of females into XX male individuals, the pseudomales. Moreover, functional role of the three genes, tra, tra-2 and $d s x$ of Anastrepha, was also demonstrated by introduction of cDNA of the Anastrepha genes in intersexual Drosophila melanogaster and the development of sexually dimorphic structures were monitored. It was shown that genes tra (Ruiz \& Sanchez, 2010), tra-2 (Sarno et al., 2011) and $d s x$ (Alvarez et al., 2010) of Anastrepha promoted the transformation Drosophila XY male flies into females, i.e., the Anastrepha genes have changed the male splicing of the Drosophila pre-mRNAs into the female mode of splicing corroborating the role of the genes in Anastrepha sex determination. Similarly, it was demonstrated that the $d s x$ gene of Ceratitis capitata induces masculinization of transgenic XX Drosophila flies (Saccone et al., 2008).

In the embryonic RNAi experiments with tephritid flies it was also detected that the transformation of females into XX pseudomales was usually not complete, and that fertility of pseudomales was also affected. In the XX pseudomales asymmetric and/or disformed testes and gynandromorphs were detected in Ceratitis capitata (Pane et al., 2002; Salvemini et al., 2009), Bactrocera dorsalis (Liu et al., 2015), and in Anastrepha sp.1 aff. fraterculus (Sarno et al., 2010). Although the XX pseudomales of Anastrepha suspensa had motile sperms, they were shown to be sterile (Schetelig et al., 2012). On the contrary, the XX pseudomales of Ceratitis capitata (Salvemini et al. 2009, Meccariello et al 2019) and of Bactrocera dorsalis (Liu et al., 2015) were fully fertile.

Most of sex determination experimental studies in tephritid fruit flies have been performed by injection of dsRNA into eggs which suppresses the function of the involved genes in the embryos. However, although sex determination also involves maternal components of genes tra and tra-2 in eggs (Pane et al., 2002; Ruiz et al., 2007a, 2007b; Sarno et al., 2010; Luo et al., 2017), no experimental demonstration of their function has been made. The present report describes the results of silencing the tra-2 expression in adult females demonstrating that the tra- $2^{\text {mat }}$ is essential for the sex determination hierarchy in Anastrepha sp.1 aff. fraterculus.

\section{Method}

\subsection{Biological Material}

The present study was carried out with Anastrepha sp.1 aff. fraterculus, a species of the Anastrepha fraterculus complex of cryptic species (Selivon et al., 2005; Hernández-Ortiz et al., 2012, 2015; Prezotto et al. 2019). The flies derived from laboratory colonies initiated with specimens collected in guavas (Psidium guajava) from Poços de Caldas, MG, Brazil ( $\left.21^{\circ} 47^{\prime} \mathrm{S}, 46^{\circ} 33^{\prime} \mathrm{W}\right)$, which were maintained accordingly to standard procedures (Selivon et al. 2005).

\section{2 dsRNA Preparation and Injection}

For generating Aftra2dsRNA, tra-2 cDNA fragments were produced using Superscript ${ }^{\circledR}$ III First-Strand Synthesis for RT-PCR kit from total RNA ( $5 \mu \mathrm{g}$ per reaction), following manufacturer instructions using tra-2F primer. Afterwards, those fragments were amplified by PCR reaction using the following primers: tra-2F: ATGAGTCCACGTAC, tra-2R: CACGTCGCTTATCGTACGGA. The PCR was performed under the following conditions: $94^{\circ} \mathrm{C}$ for $1 \mathrm{~min}$, followed by 35 cycles at $94^{\circ} \mathrm{C}$ for $20 \mathrm{sec}, 55^{\circ} \mathrm{C}$ for $20 \mathrm{sec}$ and $72^{\circ} \mathrm{C}$ for $30 \mathrm{sec}$, followed by a final extension step of $72^{\circ} \mathrm{C}$ for 10 minutes. PCR products were purified using GeneJET PCR Purification Kit (Thermo) and then sequenced using ABI Prism Big Dye Terminator Cycles Sequencing Ready Reaction kit, both following manufacturer instructions. Obtained sequences were manually inspected in BioEdit Sequencies Alignment Editor (v.7.0.9.0). Purified fragments were used in a second PCR using tra-2F and tra-2R primers containing $\mathrm{T} 7$ promoter sequences, T7tra-2F: ATGAGTCCACGTACTAATACGACTCACTATAGGGAGA and T7tra-2R: CACGTCGCTTATCGTACGGATAATACGACTCACTATAGGGAGA. The PCR cycling was as following: $94^{\circ} \mathrm{C}$ for $1 \mathrm{~min}$, followed by 35 cycles at $94^{\circ} \mathrm{C}$ for $20 \mathrm{sec}, 65^{\circ} \mathrm{C}$ for $30 \mathrm{sec}$ and $72^{\circ} \mathrm{C}$ for $30 \mathrm{sec}$, followed by a final extension step of $72{ }^{\circ} \mathrm{C}$ for 10 minutes. Product samples were analyzed by electrophoresis in $1 \%$ agarose gels in 1x TAE buffer with 1x GelRedTM Nucleic Acid Gel Stain, 1x using TAE as running buffer for 30 minutes at constant 60V and 60mA, as recommend by Sambrook et al. (1989). Electrophoresis gels were analyzed under UV transilluminator, recorded (Viber-Laumat) and transferred to computer for analysis. After confirming the presence of the fragments, DNA was measured by NanoDropTM 1000 Sepectrophotometer (Thermo Scientific), and this product was used for dsRNA synthesis. 
About $1 \mu \mathrm{g}$ of the product was used to produce Aftra2dsRNA by in vitro reaction with T7 polymerase for 16 hours using Megasript kit (Ambion). dsRNA products were purified by precipitating in lithium chloride ( $\mathrm{LiCl}$ ), following manufacturer instructions, and resuspended in injection buffer $\left(5 \mathrm{mM} \mathrm{KCl}, 0.1 \mathrm{mM} \mathrm{NaH}_{2} \mathrm{PO}_{4}, \mathrm{pH} 6.8\right)$ to a final concentration of $2 \mu \mathrm{g} / \mu \mathrm{l}$, measured with NanoDropTM 1000 Spectrophotometer (Thermo Scientific). Samples were used immediately or stored at $-80^{\circ} \mathrm{C}$.

For injection, solution of Afltra2dsRNA at the concentrations of $1.8 \mu \mathrm{g} / \mu \mathrm{L}, 1.2 \mu \mathrm{g} / \mu \mathrm{L}$ and $0.6 \mu \mathrm{g} / \mu \mathrm{L}$ were prepared in buffer containing $5 \mathrm{mM} \mathrm{KCL}, 0.1 \mathrm{mM}, \mathrm{NaH}_{2}-\mathrm{PO}_{4}$, pH 6.8 (Sarno et al., 2010). Groups of 10 adult females under cold anesthesia were injected with dsRNA with a fine tip glass needle (Eppendorf) at the ventro-lateral pleura between abdominal segments 3 and 4 . Three volumes of dsRNA solution $(1 \mu \mathrm{L}, 0.7 \mu \mathrm{L}$ and $0.5 \mu \mathrm{L}$ ) from each of the three concentrations were tested as well as control injections of plain buffer. The injected females were transferred to cages provided with water and food ad libitum and inspected for the next 24 h. The female survival was higher (70 to $80 \%$ ) at the dsRNA concentration of $1.2 \mu \mathrm{g} / \mu \mathrm{L}$ in a volume of $0.7 \mu \mathrm{L}$, similarly to the survival of females injected with plain buffer. These parameters for the dsRNA injection were employed in all the experiments. Number of flies, as well as experiment details and statistical methods of analysis will be explained in the Results for the sake of clarity.

\subsection{Experimental Design}

The study comprises three sets of experiments: Firstly, tests for the demonstration that the Afltra2dsRNA induces the transient silencing of gene tra-2 in the adult females; secondly, analysis of sex ratio of progenies produced by the treated females during the period of tra-2 silencing; third, analysis of the morphology, of karyotypes and fitness parameters of the F1 males and morphology of F1 females from these progenies.

\subsubsection{Maternal tra-2 Silencing}

Efficiency of the Afltra2dsRNA in promoting tra-2 gene silencing was tested by RT-PCR. For that, 18 females were injected with Afltra2dsRNA and an equal number with plain buffer (BC). The injected females were separated in groups of 3 for RNA extraction in days $0,3,6,9,12$ and 15 after injection ( 0 corresponding to the day of injection). RNA was extracted from total adult flies and employed to produce cDNA using SuperScript III ${ }^{\circledR}$ (Thermo Scientific) following the fabricant instruction with tra-2 specific primers (F: 5' AGAGTTGGAATGAGTCCACGTAC 3'; R: 5' CACGTCGCTTATCGTACGGA 3). Primers were constructed using NCBI Primer-Blast tool, from tra-2 cDNA of Anastrepha obliqua (GenBank FN658607). For the RT-PCR reaction $10 \%$ of cDNA was employed and the cycles were as follows: 1 minute at $94{ }^{\circ} \mathrm{C}$, followed by 32 amplification cycles at 15 seconds at $94{ }^{\circ} \mathrm{C}, 15$ seconds at $57{ }^{\circ} \mathrm{C}$ and 30 seconds at $72{ }^{\circ} \mathrm{C}$, and finally and final extension step of 10 minutes at $94^{\circ} \mathrm{C}$. Then, the reactions were analyzed by running gel electrophoresis (agar $1.5 \%$ in TAE buffer) stained with GelRed ${ }^{\circledR}$. Gel runs were analyzed under UV transilluminator (Viber-Loumat), photographed and images were edited by Photoshop 6.0 (StatSoft, Inc ${ }^{\circledR}$ ).

\subsubsection{Analysis of Sex Ratio}

Four replicate experiments (A, B, C, D) for testing the effect of dsRNA, and two controls, one with plain buffer (BC) and the other without any treatment (UC) were made. In each experiment, pupae of $A$. sp. 1 aff. fraterculus from colony were transferred to cages until emergence of adults. Soon as they emerged males and females were separated in individual cages and provided with water and food ad libitum. For analysis of sex ratio, 50 pairs of mature virgin flies (15-17 days) were transferred to standard insect rearing cubic cages (20 cm edge), and guava fruits were provided for oviposition and larvae development. After a week, guavas were transferred to flasks, containing vermiculite. After 15-20 days, pupae were collected and maintained under standard condition until emergence of adults. Analysis of imagoes from each progeny revealed the sex ratio produced by females before of dsRNA and buffer (BC) treatments. At the end of this one-week pre-injection period, females of each replica were injected with Afltra2dsRNA, others were injected with buffer (BC) and a non-injected untreated group of females (UC) was secured. To each group guavas were furnished for oviposition during a week to obtain progenies and this procedure was repeated for the next four weeks. The sex ratio of emerged adults produced at each experimental and control group during each of the five weeks the experiment lasted was registered. Additionally, groups of F1 males from the offspring of the experimental replicas were secured along the experiments for karyotype analysis of their as well as for their mating behavior, fertility, morphology of reproductive structures, production and transfer of sperms. Morphology of F1 females was also analyzed.

\subsubsection{Karyotype Analysis}

For this analysis, $40 \mathrm{~F} 1$ males derived from progenies of dsRNA injected females of each experimental replica and 40 from the control group (BC) were karyotyped as described by Selivon and Perondini (1967). Briefly, the 
testicles of recent emerged males ( 1 to 2 days after emergence) were dissected, transferred to a $0.2 \%$ solution of sodium citrate for $10 \mathrm{~min}$, immersed in a drop of $2 \%$ acetic orcein, and squashed between slide and coverslip. Analysis of the preparations was made under a BX60 Olympus microscope under regular illumination or phase contrast. Digital images were captured by a DC100 Leica camera coupled to the microscope and edited by Photoshop 6.0 (StatSoft, Inc. ${ }^{\circledR}$ ).

\subsubsection{Morphology and Reproductive Performance of Males}

For these tests, $20 \mathrm{~F} 1$ males at the $1^{\text {st }}$ week and 20 at the $3^{\text {rd }}$ week from each experimental replica and from the control group $(\mathrm{BC})$ were individually transferred to cages together with 2-3 virgin females from the stock. These cages were provided with water, food, and guavas as oviposition site for two weeks. The guavas from each replica were retrieved and maintained until pupae recovering. After emergence, adults were employed for in cross fertility tests. During this period, 5 males from replica A, 5 from replica B and 6 from replica C, died for unknown causes. Hence, the analysis of F1 male characteristics were based on 35 males from each experimental replica $\mathrm{A}$ and $\mathrm{B}$, and 34 from replica $\mathrm{C}$.

The males from each cross were observed daily for two weeks and their behavior related to courtship and mating were registered: everted anal pouch membranes (indicative of pheromone emission), wing fanning and copulas or copula attempts (Gomes-Cendra et al., 2011). After this period, the guavas were retrieved, maintained until adult emergence, and the presence of progenies derived from these fruits indicated fertility of the crosses.

After these two weeks, the F1 males were retrieved, anesthetized under cold and examined in a stereomicroscope for the external morphology of their terminalia. After, they were dissected for analysis of their internal reproductive organs. The testicles were removed and squashed between slide and coverslip in a drop of insect Ringer and examined for the presence of motile sperm. The external terminalia of the females involved in these crosses were also examined. After female dissection, their spermathecae were removed, squashed in drop of insect Ringer under a slide and coverslip, and examined for the presence of sperms. Hence, it was ascertained whether each one of the males was fertile or not and this information correlated with their morphological and other biological parameters analyzed. These analyses were made in a BX60 Olympus microscope under phase contrast. Digital images were taken by a DCC Leica camera coupled to the microscope and edited by Photoshop 6.0 software (Statsoft Inc. ${ }^{\circledR}$ ).

\section{Results}

\subsection{Maternal tra-2 Silencing}

In females injected with buffer (BC control) amplification of a fragment of about $300 \mathrm{bp}$ was detected along three weeks after injection with no visible differences in the size of the tra-2 fragment compared to the fragment amplified from non-treated control females (UC). The fragments were sequenced and was confirmed that they correspond to tra-2 sequences (Sarno et al., 2010) (data not shown). In Afltra2dsRNA injected females, amplification of a fragment of $300 \mathrm{bp}$ was observed at the day of injection (day 0 ). However, on the 3rd day after injection a faint band was still obtained, followed by a period in which no amplification of tra-2 was detected, but on day 15 a faint fragment was detected again, indicating that expression of tra-2 was being resumed (Figure $2)$. 


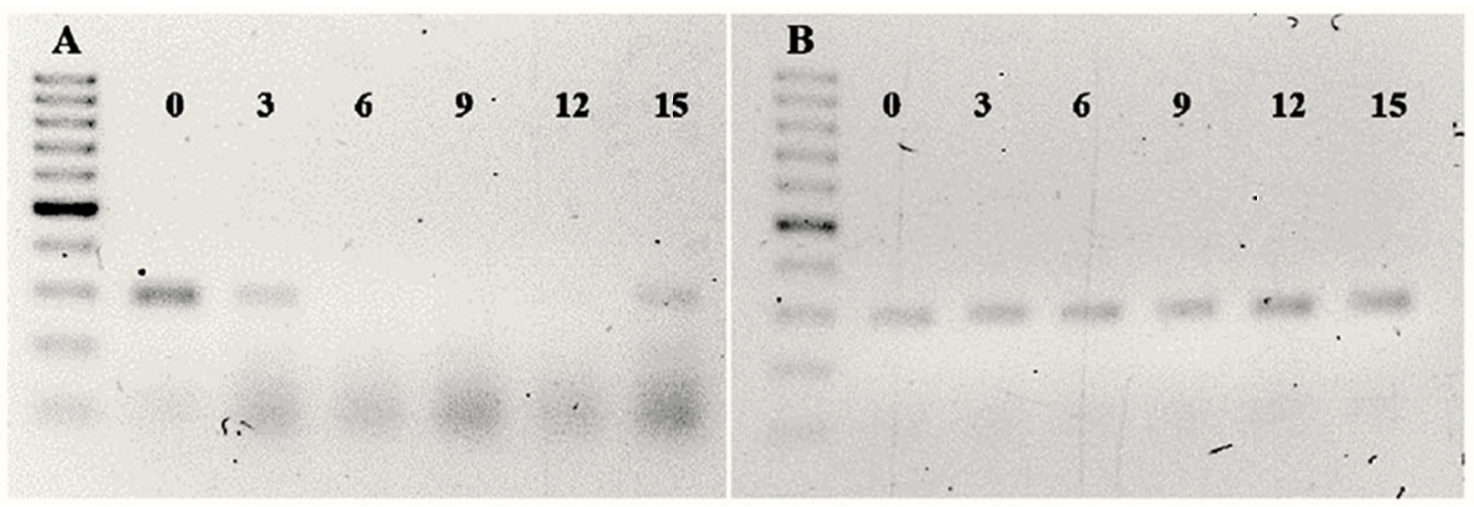

Figure 2. Silencing of gene tra-2 in adult females. (A) Expression of tra-2 in females injected with AfItra2dsRNA and (B) in females injected with plain buffer. The numbers indicate the day of injection (day 0) and thereafter. A fragment of tra-2 with $300 \mathrm{bp}$ is seen in the controls (B) during the 15 days; on the treated females (A) a fragment of 300 bp is seen at day 0 , a faint band was found in day 3 , and no fragment was amplified from day 6 to day 12, but a faint band appears again at day 15. Black and white colors inverted in the gel photo for clarity. The left columns in both figures are the molecular scale $1000 \mathrm{bp}$

\subsection{Progeny Analyses}

\subsubsection{Sex Ratio}

The effects of parental RNAi were analyzed in a significant number of offspring produced by treated females of the four replicates (A, B, C, D) and two control groups (BC and UC) (Table 1). Firstly, analyses of the progenies produced by females previously to the dsRNA treatments (day 0 ) showed the expected 1:1 sex ratio (Table 1 and Figure 3). On the contrary, the sex ratio of total offspring produced during the following 4 weeks by females injected with Afltra2dsRNA has deviated significantly from 1:1 in favor of males (Table 1). The proportion of males that were about $50 \%$ before treatment, gradually increased during the first three weeks and returned to about 1:1 in weeks 4 and 5 (Figure 3A). This pattern was observed for the four replicas of the experiment and although small differences between replicas have been observed the Kruskal-Wallis test indicate no statistical differences between the distributions $(\mathrm{H}(3, \mathrm{n}=24)=2.04, \mathrm{p}=0.557)$. The progenies sex ratio produced by females from both control groups, $\mathrm{BC}$ and $\mathrm{UC}$, fluctuate during the 5 weeks but did not differed significantly from the 1:1 ratio (Table 1 and Figure 3A). The highest deviation occurred during the 3rd week attaining 69.3\% of males in replica $\mathrm{D}$. The overall average increase in male frequencies above the expected $50 \%$ in weeks $1,2,3$ and 4 was of $13.95 \%$ (Figure 3B). This figure also makes evident that the deviation in the sex ratio occurred in the progenies during the period that the tra-2 gene was silenced in the injected parental females and progressively returned to about 1:1 after the resuming of tra-2 activity.

Table 1. Sex ratio among adult flies of total progenies before and after injection of RNAi, and chi-square tests

\begin{tabular}{|c|c|c|c|c|c|c|c|c|c|}
\hline \multirow{2}{*}{ Treatment } & \multicolumn{5}{|c|}{ Before injection } & \multicolumn{4}{|c|}{ After injection } \\
\hline & Groups & $\mathrm{N}$ & $\%$ Males & $\chi^{2}$ & $P$ & $\mathrm{~N}$ & $\%$ Males & $\chi^{2}$ & $\mathrm{p}$ \\
\hline \multirow{4}{*}{ Aftra2dsRNA } & A & 169 & 52.6 & 0.379 & 0.538 & 213 & 63.8 & 15.793 & $<0.001^{*}$ \\
\hline & B & 47 & 46.8 & 0.085 & 0.771 & 275 & 58.9 & 8.378 & $0.003 *$ \\
\hline & $\mathrm{C}$ & 40 & 45.0 & 0.225 & 0.635 & 311 & 61.1 & 14.868 & $<0.001^{*}$ \\
\hline & D & 30 & 50.0 & 0.033 & 0.856 & 311 & 59.2 & 10.084 & $0.001 *$ \\
\hline Buffer control & $\mathrm{BC}$ & 169 & 47.3 & 0.378 & 0.538 & 305 & 50.2 & 0.004 & 0.949 \\
\hline Untreated & UC & 36 & 47.2 & 0.028 & 0.867 & 405 & 50.4 & 0.010 & 0.920 \\
\hline
\end{tabular}



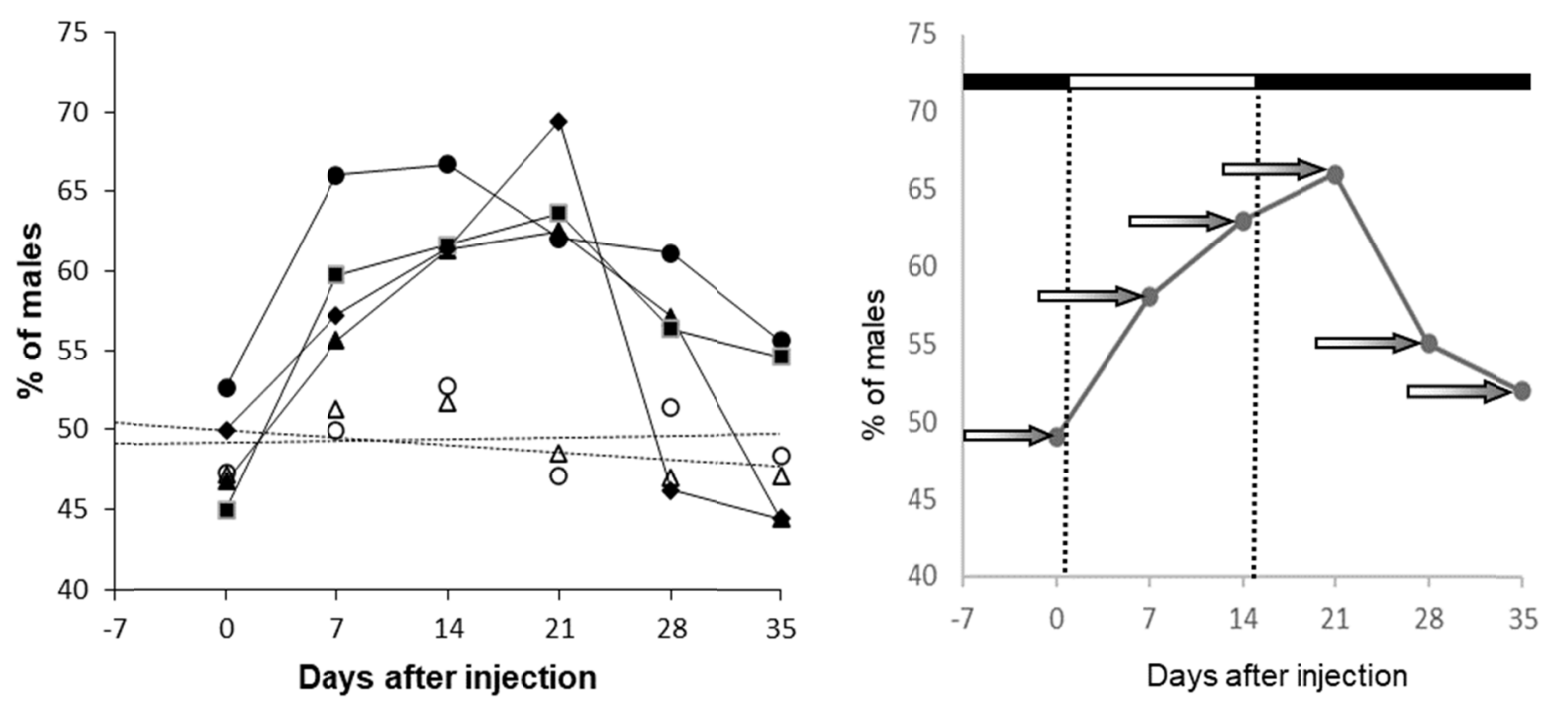

Figure 3. Sex ratio of adults in progenies of injected females with AfItra2dsRNA. (A) Injection was made on day 0 . The filled points indicate the sex ratio of the four replicate experiments and the open points the sex ratio of the two control crosses. (B) The bar at the top indicates the period of activity (black) and silencing (clear) of tra- 2 in the parental females. The points show the mean sex ratio of the four experimental replicas, and the days were egg deposited by the females were collected and maintained until emergence of adults. The arrows indicate the approximated time when the collected eggs start their formation in the ovaries, e.g., eggs deposited on day 7 started development 7-15 days before. As shown by the two vertical dashed lines, the eggs in samples with deviation of sex ratio in favor of males (days $7,14,21$ ) had developed entirely or large part of time during the period that tra-2 were inactive in the parental females

\subsubsection{Karyotype Analysis}

Analysis of 40 males per experimental and control groups showed that a proportion of the males produced by dsRNA injected females were pseudomales bearing a XX sex chromosome pair while the majority were regular males exhibiting the XY chromosomes constitution (Table 3 and Figure 4). This is clearly detected since $A$. sp. 1 aff. fraterculus has a small Y small heterochromatic chromosome (Selivon et al 2005; Goday et al 2006). The mean frequency of pseudomales $(12.8 \%)$ is not significantly different from the mean increase in male frequency of $13.95 \%$ (above $50 \%$ ) as observed in the sex ratio analysis above described $\left(\chi^{2}\right.$ Yates $=0.091, p=0.77$ ). The data indicate that the sex ratio deviation is due to the transformation of a fraction of genotypic XX embryo into pseudomales and not to differential mortality of females as attested by the rate of adult emergence in progenies of the treated females (Table 2).

Table 2. Rate of adult emergence in control and in crosses of dsRNA injected females and chi-square tests

\begin{tabular}{|c|c|c|c|c|}
\hline \multirow{2}{*}{ Samples } & \multirow{2}{*}{ No. of pupae } & \multicolumn{2}{|c|}{ Emergence } & \multirow{2}{*}{ Contingence $\mathrm{p}$-values } \\
\hline & & $\mathrm{N}$ & $\%$ & \\
\hline $\mathrm{A}$ & 302 & 213 & 70.5 & 0.801 \\
\hline B & 362 & 275 & 75.9 & 0.772 \\
\hline $\mathrm{C}$ & 423 & 311 & 73.5 & 0.997 \\
\hline Control & 417 & 305 & 73.1 & $\mathrm{X}$ \\
\hline
\end{tabular}


Table 3. Number of males with XY or XX sex chromosomes in the experimental and control groups

\begin{tabular}{lll}
\hline Groups & $\mathrm{XY}$ & $\mathrm{XX}(\%)$ \\
\hline Control & 34 & 0 \\
A & 32 & $5(13.5)$ \\
B & 28 & $3(9.7)$ \\
C & 27 & $3(10.0)$ \\
D & 14 & $4(13.3)$ \\
\hdashline Total (A-D) & 92 & $15(12.8)$ \\
\hline
\end{tabular}

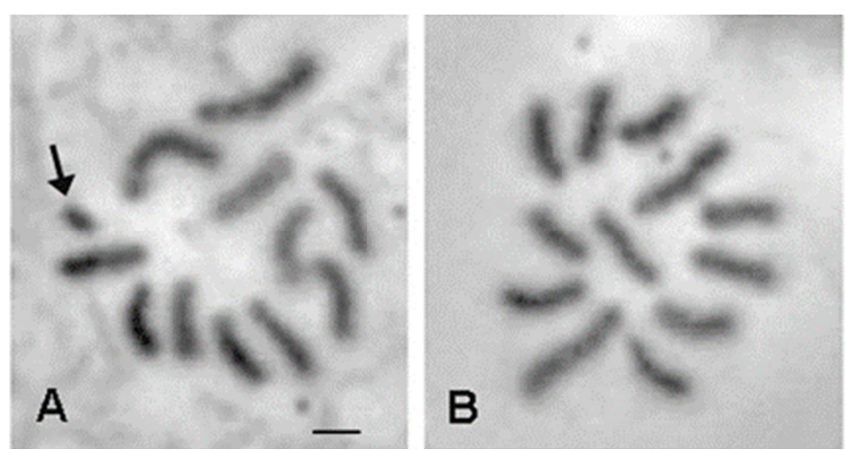

Figure 4. Mitotic divisions in male testicles. (A) Metaphase of a regular male with the small $\mathrm{Y}$ chromosome (arrow); (B) metaphase of a F1 male from the progeny of a Afltra-2dsRNA treated $A$. sp. 1 female with 12 chromosomes without the $\mathrm{Y}$ chromosome, thus being a pseudomale with a XX sex chromosome constitution. Scale bar, A, B $=10 \mu \mathrm{m}$

\subsubsection{Morphology and Reproductive Performance of Males}

For these analyses F1 males from the progenies of Afltra2dsRNA treated females were individually crossed to females from the stock and guavas were furnished for oviposition and the flies observed for two weeks. After this, the guavas were retrieved and maintained until adult emergence for determination of each cross fertility. Similar crosses were made with F1 males in the progenies of buffer injected females (control group).

Analysis of adult emerged from the retrieved guavas showed that there were no significant differences in emergence rate between replicas (contingence table, $\chi_{\text {Yates }}^{2}=0.31, \mathrm{p}=0.856$ ), hence the data were pooled. Among the 104 tested F1 males, 72 (69.2\%) were fertile and the produced progenies were composed by male and female flies. However, for the other $32(30.8 \%)$ F1 males no progenies were recovered. The number of fertile and unfertile males, however, are significantly different from the control crosses since $32(94.1 \%)$ were fertile and only $2(5.9 \%)$ were infertile (contingence table, $\chi^{2}$ Yates $=8.547, \mathrm{p}=0.035^{*}$ ).

The F1 males, after the 2 weeks period of observation, was retrieved from each cross and individually examined, no abnormalities being found in their external terminalia. It was observed that the males from each replica and from the control group showed normal courtship behavior, like everted anal pouch membranes, wing fanning and that all of them have attempted or have indeed copulated. Then, the males had their testicles dissected out and motile sperms were found in all of them. However, in $4.8 \%$ of them asymmetrical testicles were found, one was apparently normal, but the other was larger and spherical (Figure 5). These alterations were not found in the males of the control group.

Dissection of females from the 72 fertile crosses showed that sperms were clearly found in their spermathecae but among the females from the 32 infertile crosses two classes were found: In 24 (75.0\%) of them sperms were not found in the spermathecae but in $8(23.5 \%)$ sperms were indeed transferred. The morphological analysis of the $\mathrm{F} 1$ females from the progenies of tra2dsRNA treated females have normal internal structures but one female had the ovipositor shorter than normal and without the terminal opening (Figure 5). 


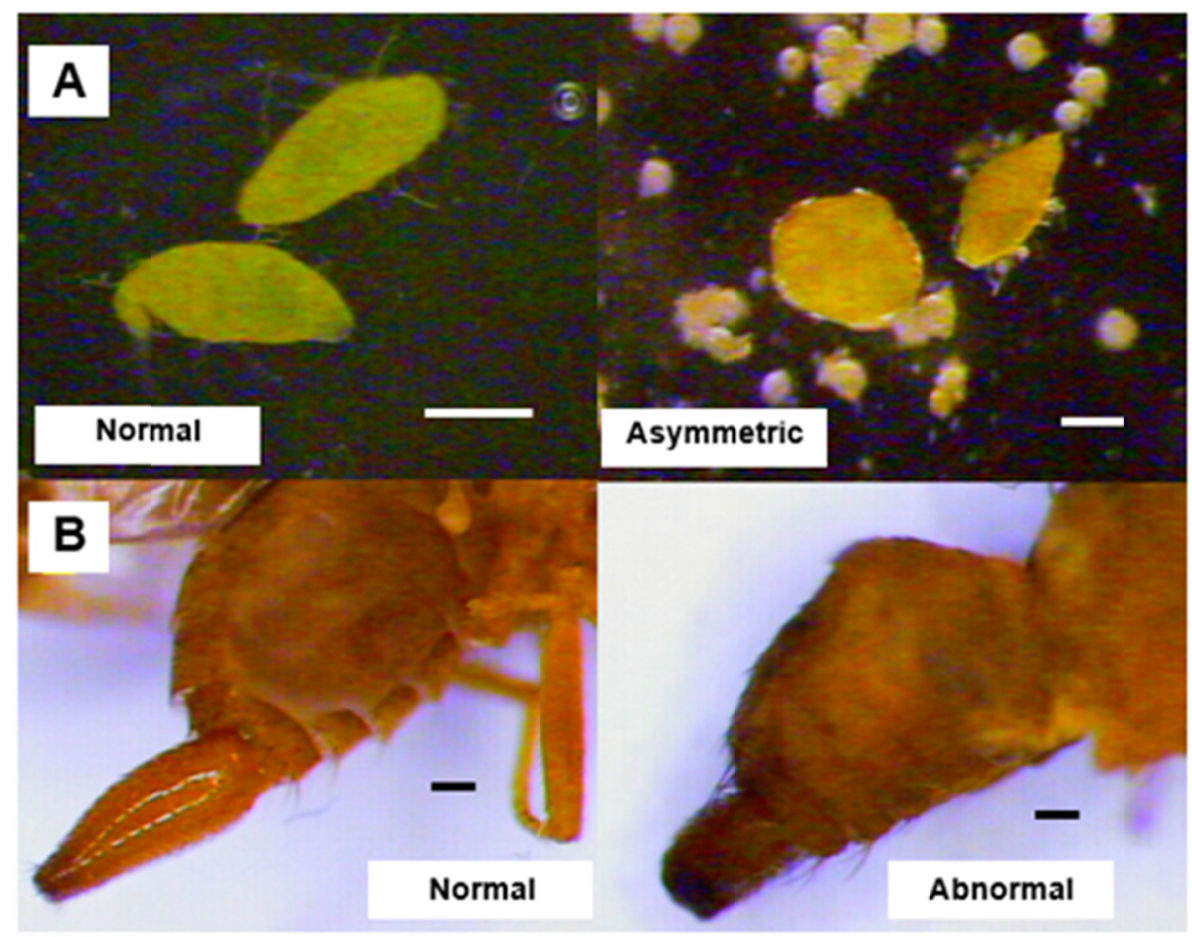

Figure 5. Morphological aspects of testicles and of the female external genitalia. (A) Regular and asymmetric testicles and in (B) regular and abnormal ovipositor found within the progenies of Afltra2dsRNA injected females. Scale bars, A, B $=300 \mu \mathrm{m} ; \mathrm{C}, \mathrm{D}=250 \mu \mathrm{m}$

\section{Discussion}

Silencing of gene tra-2 by dsRNA injection in the adult females were achieved in the present study. The data suggested that inactivation of the gene might have occurred soon after injection. In B. dorsalis it was shown that inhibition of $d s x$ gene by parental dsRNA treatment started 1 hour after injection (Chen et al., 2008). However, in the present analysis a faint amplified fragment was still visible on day 3 after treatment. It could be remnants of stocked tra-2 RNA that were slowly being employed and depleted or due to silencing in distinct asynchronous females. On day 15 , a faint fragment appears again indicating that tra-2 activity was being resumed not abruptly but in increasing fraction of oocytes and/or due to asynchronous development of distinct females. Similar gradual recovery of gene activity after pRNAi silencing were described for $d s x$ activity in Bactrocera dorsalis (Chen et al., 2008) and in tra-2 activity in the Asian citrus psyllid Diaphorina citri (Yu \& Killiny, 2017).

Since the amplification of tra-2 was made from the parental females "in toto", including ovaries, the data indicate that during the three weeks of silencing, the treated females produced oocytes depleted of the tra- $2^{\text {mat }}$ RNA or its protein. Hence, if the auto-regulatory function of gene tra in the oocytes was really blocked by the absence of tra-2 $2^{\text {mat }}$ it would be expected that during the period of tra-2 inactivity the females will produce offspring with altered sex ratio in favor of males and with the formation of XX pseudomales, as shown by embryonic silencing by dsRNA of the gene tra-2 in this species (Sarno et al., 2010). Indeed, females under the Afltra2dsRNA treatment produced progenies with altered sex ratio in favor of males. The frequency of male gradually increases in the weeks following the dsRNA treatment until the $3^{\mathrm{dr}}$ week and decrease toward 1:1 ratio thereafter. It is relevant to note that the frequency of males never reached $100 \%$ or closely, what would be expected if every oocyte produced during the inhibition of the gene tra-2 did not had the $\operatorname{tra}-2^{\text {mat }}$ factor. In species of frugivorous tephritid maturation of oocytes may take a variable timing interval to develop even among females of the same species as showed, for example, in Anastrepha fraterculus (Cardoso et al., 2006); Bartolucci et al., 2006), A. serpentina (Martinez et al., 1995), A. suspensa (Kendra et al., 2006) and Bactrocera dorsalis (Chou et al., 2012). Since the present analyses were made with pooled females the results might be explained by asynchronous development of the ovarioles or even the ovaries of a given female or between distinct females which could limit the number of oocytes depleted of tra- $2^{\text {mat }}$. However, the alteration in the sex ratio attained its maximum value $(69.3 \%$ of males) at day 21 when the activity of gene tra-2 in the parental female had already 
been resumed. This apparent inconsistence may be explained, considering that the eggs collected at day 21 had initiated their development 7-10 days before, thus during the period that tra-2 was still silenced in the parental female, as indicated in Figure 3B. Moreover, the fact that absorption of substances by the developing oocyte occurs only during the initial stages of their development (vitellogenesis stage), or in other words, before the stages the egg covers, vitelline and chorion membranes, are deposited in the oocyte (Telfer, 2009), may also be an explanation for the observed results.

In species of tephritid fruit flies, as in other insect species (Sánchez, 2008; Verhlust et al., 2010; Bopp et al., 2014), the increase in male frequency following injection of tradsRNA and/or tra2dsRNA in embryos cause the default expression of zygotic tra leading to the development of a fraction of genotypic XX embryos to development as males, the so called XX pseudomales (Salvemini et al., 2009; Sarno et al., 2010; Schetelig et al., 2012; Liu et al., 2015). It shall made clear that in the present study the XX pseudomales were identified by chromosome analysis in a sample of F1 males derived from the sex ratio analysis. However, the karyotypes of another sample of 104 sister F1 males could not be determined because they were employed in the crosses to evaluate their reproductive status. Thus, one may assume that among these $104 \mathrm{~F} 1$ males a fraction must have had the XX chromosome pair while the majority were regular males bearing XY sex chromosomes. The analysis of these $104 \mathrm{~F} 1$ males showed they exhibited the typical mating behavior of the species herein analyzed (Selivon et al., 2005; Roriz et al., 2017). Hence, if pseudomales of $A$. sp.1 were present, they would show similar biological characteristics as the pseudomales of $A$. suspensa that although displaying regular mating behavior and producing motile spermatozoids, are sterile (Schetelig et al., 2012). Another aspect suggestive that the pseudomales herein produced were sterile is the fact that single sex progenies composed only by females were not found among the 72 fertile crosses of the present analysis. These only female offsprings would be produced by XX pseudomales if they were fertile as was observed in C. capitata (Savemini et al., 2009) and B. dorsalis (Liu et al., 2015). Hence, as pointed out by Schetelig et al. (2012), it seems that in C. capitata and B. dorsalis male fertility is not dependent of the Y chromosome while in A. suspensa the Y chromosome may carry factor(s) related to fertility. The results herein obtained for $A$. sp. 1 aff. fraterculus, seems to be in line with these inferences.

Sterile crosses in which sperms were not transferred may be related to failure to complete the copula or to alteration in the female receptivity to mate, as shown in A. sp.1 from Argentina (Abrahams et al., 2011).

Since every male from the offspring of treated females, including the existent XX ones, was able copulate it was not expected morphological alterations in their terminalia, a fact that indeed was observed, as well as the presence of mobile sperms. Moreover, in the present study some of these males had altered testicles, usually hypertrophied ones and these characteristics were similar to those observed for males that develop from eggs of A. suspensa in which gene tra-2 had been silenced by injection of tra2dsRNA (Schetelig et al., 2012). Another morphological alteration in the progenies of treated females is a rare case of a female that had a deformed ovipositor. This morphological malformation seems to be similar to that described in $B$. dorsalis treated by parental $d s x$ dsRNA in which a fraction of the F1 females showed shorter ovipositor (Chen et al., 2008).

Hence, in the present study it is assumed that in the absence of $t r a-2^{\text {mat }}$ in XX embryos the auto-regulatory expression of the zygotic tra were not activated and truncated/default Tra protein must have been produced leading XX embryos to follow male development. Clearly, regular XY embryos are not affected by the treatment given origin to regular male flies. It must be noted that the sex ratio deviation in favor of males was not caused by differential mortality of females as attested by the rate of adult emergence in progenies of the treated females (Table 2) but was due to the transformation of a fraction of genotypic XX embryos into pseudomales. This effect may be useful to generate improvements in the mass rearing of flies, since sexing of the insects is a significant bottleneck for the application of the SIT to insect pest. The production of pseudomales may be enhanced by association of dsRNA of the genes tra and tra-2 as reported for A. suspensa (Schetelig et al., 2012), and the dsRNAs for adult females could be delivered by other methods more suitable for the large-scale application in the biofabrics (Katoch et al., 2013; Zhang et al., 2013; Yu et al., 2013; Pomerantz \& Hoy, 2015; Song et al., 2017). Improvements in modern and more sustainable technologies, as SIT, integrated with other control methods may lead to a more environmentally friendly strategies for insect pest control (Liedo et al., 2021).

\section{Conclusion}

The present report describes the results of the transient silencing of gene transformer-2 by parental dsRNA interference methodology in $A$. sp. 1 aff. fraterculus. It is concluded that the tra- $2^{\text {mat }}$ in the egg is a necessary factor for the auto-regulatory activity of embryonic gene transformer, the key gene for the sex determination 
hierarchy in Anastrepha. This effect may be useful to improve more sustainable technologies for fruit fly control such as SIT.

\section{Acknowledgements}

This work was supported by grants from the Fundação de Amparo à Pesquisa do Estado de São Paulo, Brazil (FAPESP, 2016/00782-7) to DS. PEV and ESC were recipients of a MS degree studentships from CNPq (respectively 134297/2014 and 133315/2017). The authors thank Mr. Carlos Eduardo Lopes for laboratory technical support (USP) and to Dr. Bruno Rossini (Instituto de Biotecnologia, Botucatu Campus, UNESP) for the help with the dsRNA synthesis.

\section{References}

Abraham, S., Goane, L., Cladera, J., \& Vera, M. T. (2011). Effects of male nutrition on sperm storage and remating behavior in wild and laboratory Anastrepha fraterculus (Diptera: Tephritidae) females. Journal of Insect Physiology, 57(11), 1501-1509. https://doi.org/10.1016/j.jinsphys.2011.08.004

Alvarez, M., Ruiz, M. F., \& Sánchez, L. (2009). Effect of gene doublesex of Anastrepha on the somatic sexual development of Drosophila. PLoS ONE, 4, e5141. https://doi.org/10.1371/journal.pone.0005141

Bachtrog, D., Mank, J. E., Peichel, C. L., Kirkpatrick, M., Otto, S. P., Ashman, T.-L., ,.. Vamosi, J. C. (2014). Sex Determination: Why so many ways of doing it? PLoS Biol, 12(7), e1001899. https://doi.org/ 10.1371/journal.pbio.1001899

Bartolucci, A., Vera, M. T., Yusef, V., \& Oviedo, A. (2006). Morphological characterization of the reproductive system of irradiated Anastrepha fraterculus. Proc. $7^{\text {th }}$ International Symposium on the Fruit Flies of Economic Importance (pp. 45-52). Moscamed, Brazil.

Belote, J. M., McKeown, M., Boggs, R. T., Ohkawa, R., \& Sosnowski, B. A. (1989). Molecular genetics of transformer, a genetic switch controlling sexualdifferentiation in Drosophila. Developmental Genetics, 10, 143-154. https://doi.org/10.1002/dvg.1020100304

Bopp, D., Saccone, G., \& Beye, M. (2014). Sex determination in insects: Variations on a common theme. Sexual Development, 8, 20-28. https://doi.org/10.1159/000356458

Cardoso, V. V., Ferreira, M. P., Montagner, J. M., Fernandez, C. G., Moreira, J. C., \& Oliveira, A. K. (2002). The effects of constant and alternating temperatures on the reproductive potential, life span, and life expectancy of Anastrepha fraterculus (Wiedmann) (Diptera: Tephritidae). Brazilian Journal of Biology, 64, 775-786. https://doi.org/10.1590/S1519-69842002000500006

Chen, S.-L., Dai, S.-M., Lu, K.-H., \& Chanf, C. (2008). Female-specific doublesex dsRNA interrupts yolk protein gene expression and reproductive ability in oriental fruit fly, Bactrocera dorsalis (Hendel). Insect Biochemistry and Molecular Biology, 38, 155-165. https://doi.org/10.1016/j.ibmb.2007.10.003

Chou, M. Y., Mau, R. F. L., Jang, E. B., Vargas, R. I., \& Piñero, J. C. (2012). Morphological features of the ovary during oogenesis of the Oriental fruit fly, Bactrocera dorsalis, in relation to the physiological state. Journal of Insect Science, 12. https://doi.org/10.1673/031.012.14401

Gempe, T., \& Beye, M. (2011). Function and evolution of sex determination mechanisms, genes and pathway in insects. BioEssays, 33, 52-60. https://doi.org/10.1002/bies.201000043

Goday, C., Selivon, D., Perondini, A. L. P., Greciano, P. G., \& Ruiz, M. F. (2006). Cytological characterization of sex chromosomes and ribosomal DNA location in Anastrepha species (Diptera, Tephtiridae). Cytogenetics and Genome Research, 114, 70-76. https://doi.org/10.1159/000091931

Gomes-Cendra, P., Calcagno, G., Belluscio, L., \& Vilard, J. C. (2011). Male courtship behavior of the South American fruit fly Anastrepha fraterculus, from an Argentinean laboratory strain. Journal of Insect Science, 11, 1-18. https://doi.org/10.1673/031.011.17501

Häcker, I., \& Schetelig, M. F. (2021). Genome editing for insect pest control: curseor blessing? In J. Hendrichs, R. Pereira, \& M. J. B. Vreysen (Eds.), Area Wide Integrated Pest Management: Development and Field Application (pp. 824-842). Taylor \& Francis Group.

Hediger, M., Henggeler, C., Meier, N., Perez, R., Saccone, G., \& Bopp, D. (2010). Molecular characterization of the key switch $\mathrm{F}$ provides a basis forunderstanding the rapid divergence of the sex-determining pathway in thehousefly. Genetics, 184, 155-170. https://doi.org/10.1534/genetics.109.109249 
Hendrichs, J., Vera, M. T., De Meyer, M., \& Clarke, A. K. (2015). Resolving cryptic species complexes of major tephritid pests. ZooKeys, 540, 5-39. https://doi.org/10.3897/zookeys.540.9656

Hernández-Ortiz, V., Bartolucci, A., Morales-Valles, P., Frías, D., \& Selivon, D. (2012). Cryptic species of the Anastrepha fraterculus complex (Diptera, Tephritidae): A multivariate approach for the recognition of South American morphotypes. Annals of the Entomological Society of America, 105, 305-318. https://doi.org/ 10.1603/AN11123

Hernández-Ortiz, V., Canal, N., Tigrero, A., Salas, J. O., Ruíz-Hurtado, F. M., \& Dzul-Cauich, J. F. (2015). Taxonomy and phenotypic relationships of the Anastrepha fraterculus complex in the Mesoamerican and Pacific Neotropical dominions (Diptera, Tephritidae). ZooKeys, 540, 95-124. https://doi.org/10.3897/ zookeys.540.6027

Huvenne, H., \& Smagghe, G. (2010). Mechanisms of dsRNA uptake in insects and potential of RNAi for pest control: A review. Journal of Insect Physiology, 56, 227-235. https://doi.org/10.1016/j.jinsphys.2009.10.004

Katoch, R., Sethi, A., Thakur, N., \& Murdock, L. L. (2013). RNAi for insect control: current perspective and future challenges. Applied Biochemistry and Biotechnoly, 171, 847-73. https://doi.org/10.1007/s12010013-0399-4

Kendra, P. E., Montgomery, W. S., Epsky, N. D., Heath, R. R. (2006). Ovarian development in a laboratory strain of the Caribbean frui fly, Anastrepha suspensa (Diptera: Tephritidae). Proc. $7^{\text {th }}$ International Symposium on the Fruit Flies of Economic Importance (pp. 227-232). Moscamed, Brazil.

Lagos, D., Koukidou, M., Savakis, C., \& Komitopoupou, K. (2005). The transformer gene in Bactrocera oleae: the genetic switch that determines its sex fate. Insect Molecular Biology, 16, 221-230. https://doi.org/ 10.1111/j.1365-2583.2006.00717.x

Laohakieat, K., Aketarawong, N., Isasawin, S., Thitamadee, S., \& Thanaphum, S. (2016). The study of the transformer gene from Bactrocera dorsalis and $\mathrm{B}$. correcta with putative core promoter regions. $B M C$ Genetics, 17, 34 .

Liedo, P., Montoya, P., \& Toledo, J. (2021). Area-Wide Management of Fruit Flies in a Tropical Mango Growing Area Integrating the Serile Insect Techinique and Biological Control: From a Research to an Operational Programme. In J. Hendrichs, R. Pereira, \& M. J. B. Vreysen (Eds.), Area wide integrated Pest management: development and field application (pp. 197-214).

Liu, G., Wu, Q., Li, J., Zhang, G., \& Wan, F. (2015). RNAi-mediated knock-down of transformer and transformer 2 to generat male-only progeny in the oriental fruit fly, Bactrocera dorsalis (Hendel). PLoS ONE, 10, e0128892. https://doi.org/10.1145/2818302

Luo, Y., Zao S., Li, L., \& Ya, R. (2017). Isolation and Molecular Characterization of the Transformer Gene From Bactrocera cucurbitae (Diptera: Tephritidae). Journal of Insect Science, 17, 1-8. https://doi.org/10.1093/ jisesa/iex031

Martinez, I. M., Hernández-Ortiz, V., \& Luna, R. L. (1995). Desarollo y maduration sexual en Anastrepha serpentina (Wiedmann) (Diptera: Tephritidae). Acta Zoologica de Mexico, 65, 75-88.

Meccariello, A., Salvemini, M., Primo, P., Hall, B., Koskinioti, P., Dalíková, M., ... Saccone, G. (2019). Maleness-on-the- $Y(\mathrm{MoY})$ orchestrates male sex determination in major agricultural fruit fly pests. Science, 365(6460), 1457-1460.

Morrow, J. L., Riegler, M., Frommer, M., \& Shearman, D. C. (2014). Expression patterns of sex-determination genes in single male and female embryos of two Bactrocera fruit fly species during early development. Insect Molecular Biology, 23, 754-767. https://doi.org/10.1111/imb.12123

Norrbom, A., \& Foote, R. H. (1989). The taxonomy and zoogeography of the genus Anastrepha (Diptera: Tephritidae), In A. S. Robinson \& G. Hooper, (Eds.), Fruit Flies: Their Biology, Natural Enemies and Control. World Crop Pests, 3(A) (pp. 15-26). Elsevier, Amsterdam.

Norrbom, A. L., Korytkowski, C. A., Zucchi, R. A., Uramoto, K., Venable, G. L., McCormick, J., \& Dallwitz, M. J. (2013). Anastrepha and Toxotrypana: Descriptions, illustrations, and interactive keys (28th ed.). Retrieved April 9, 2017, from http://delta-intkey.com

Pane, A., De Sinone, A., Saccone, G., \& Polito, L. C. (2007). Evolutionary conservation of Ceratitis capitata transformer gene fuction. Genetics, 171, 615-624. https://doi.org/10.1534/genetics.105.041004 
Pane, A., Salvemini, M., Delli Bovi, P., Polito, L. C., \& Saccone, G. (2002). The transformer gene in Ceratitis capitata provides a genetic basis for selecting and remembering the sexual fate. Development, 129, 3715-3725. https://doi.org/10.1242/dev.129.15.3715

Peng, W., Zheng, W., Handler, A. M., \& Zhang, H. (2015). The role of the transformer gene in sex determination and reproduction in the tephritid fruit fly, Bactrocera dorsalis (Hendel). Genetica, 143, 717-727. https://doi.org/10.1007/s10709-015-9869-7

Permpoon, R., Aketarawong, N., \& Thanaphum, S. (2011). Isolation and characterization of Doublesex homologues in the Bactrocera species: B. dorsalis (Hendel) and B. correcta (Bezzi) and their putative promoter regulatory regions. Genetica, 139, 113-127. https://doi.org/10.1007/s10709-010-9508-2

Pomerantz, A. F., \& Hoy, M. A. (2015). RNAi-mediated knockgown of transformer-2 in the predatory mite Metaseiulus occidentalis via oral delivery of double-stranded RNA. Experimental and Applied Acaralogy, 65, 17-27. https://doi.org/10.1007/s10493-014-9852-5

Prezotto, L. F., Perondini, A. L. P., Hernández-Ortiz, V., Frías, D., \& Selivon, D. (2019). What can integrated analysis of morphological and genetic data still reveal about the Anastrepha fraterculus (Diptera: Tephritidae) cryptic species complex? Insects, 10, 408. https://doi.org/10.3390/insects10110408

Rendón, P., \& Enkerlin, W. (2017). Fruit flies programmes in Latin America (pp. 1-37). 3rd International Conference in Area-wide Management of Insect Pests: Integrating the Sterile Insect and related Nuclear and other Techniques, Vienna, Austria. Retrieved February 25, 2021, from http://www.naweb.ieae.org

Rendón, P., \& Enkerlin, W. (2021). Area-wide fruit fly programmes in Latin America. In J. Hendrichs, R. Pereira, \& M. J. B. Vreysen (Eds.), Area wide integrated Pest management: Development and field application (pp. 161-196).

Roriz, A. K. P., Japyassú, H. F., \& Joachin-Bravo, I. S. (2017). Incipient speciation in the Anastrepha fraterculus cryptic species complex: reproductive compatibility between $A$. sp.1 aff. fraterculus and $A$. sp.3 aff. fraterculus. Entomologia Experimentalis et Applicata, 162, 346-357. https://doi.org/10.1111/eea.12526

Ruiz, M. F., \& Sánchez, L. (2010). Effect of the gene transformer of Anastrepha on the somatic sexual development of Drosophila. The International Journal of Developmental Biology, 54, 627-633. https://doi.org/10.1387/ijdb.092917fr

Ruiz, M. F., Eirin-Lopez, J. M., Stefani, R. N., Prondini, A. L. P., Selivon, D., \& Sánchez, L. (2007). The gene doublesex of Anastrepha fruit flies (Diptera, Tephritidae) and its evolution in insects. Developmental Genes Evolution, 217, 725-731. https://doi.org/10.1007/s00427-007-0178-8

Ruiz, M. F., Milano, A., Salvemini, M., Eirin-Lopez, J. M., Perondini, A. L. P., Selivon, D., ... Saccone, G. (2007). The gene transformer of Anastrepha fruit flies (Diptera, Tephritidae) and its evolution in insects. PLoS ONE, 2, e1239. https://doi.org/10.1371/journal.pone.0001239

Saccone, G., Pane, A., \& Polito, L. C. (2002). Sex determination in flies, fruitflies and butterflies. Genetica, 116, 15-23. https://doi.org/10.1023/A:1020903523907

Saccone, G., Peluso, I., Artiaco, D., Giordano, E., Bopp, D., \& Polito, L. C. (1998). The Ceratitis capitata homologue of the Drosophila sex-determining gene sex-lethal is structurally conserved, but not sex-specifically regulated. Development, 125, 1495-1500. https://doi.org/10.1242/dev.125.8.1495

Saccone, G., Salvemini, M., \& Polito, L. C. (2011). The transformer gene of Ceratitis capitata: A paradigma for a conserved epigenetic master regulator of sex determination in insects. Genetica, 139, 99-111. https://doi.org/10.1007/s10709-010-9503-7

Saccone, G., Salvemini, M., Pane, A., \& Polito, L. C. (2008). Masculinization of XX Drosophila transgenic flies expressing the Ceratitis capitata DoublesexM isoform. The International Journal of Developmental Biology, 52, 1051-1057. https://doi.org/10.1387/ijdb.082657gs

Salvemini, M., Robertson, M., Aronson, B., Atkinson, P., Polito, L. C., \& Saccone, G. (2009). Ceratitis capitata transformer-2 gene is required to establish and maintain the autoregulation of Cctra, the master gene for female sex detemination The International Journal of Developmental Biology, 53, 109-120. https://doi.org/ $10.1387 / \mathrm{ijdb} .082681 \mathrm{~ms}$

Sánchez, L. (2008). Sex-determining mechanisms in insects. The Internationl Journal of Developmental Biology, 52, 837-856. https://doi.org/10.1387/ijdb.0723961s 
Sarno, F., Ruiz, M. F., \& Sánchez, L. (2011). Effect of the transformer-2 gene of Anastrepha on the somatic sexual development of Drosophila. The International Journal of Developmental Biology, 55, 975-979. https://doi.org/10.1387/ijdb.103279fs

Sarno, F., Ruiz, M. F., Eirin-Lopez, J. M., Perondini, A. L. P., Selivon, D., \& Sánchez, L. (2010). The gene transformer-2 of Anastrepha fruit flies (Diptera, Tephritidae) and its evolution in insects. BMC Evolutionary Biology, 10, 140. https://doi.org/10.1186/1471-2148-10-140

Schetelig, M. F., Milano, M., Saccone, G., \& Handler, A. M. (2012). Male only progeny in Anastrepha suspensa by RNAi-induced sex reversion of chromosomal females. Insect Biochemistry and Molecular Biology, 42, 51-57. https://doi.org/10.1016/j.ibmb.2011.10.007

Selivon, D., \& Perondini, A. L. P. (1997). Evaluation of techniques for C and ASG banding of mitotic chromosomes of Anatrepha species (Diptera, Tephritidae). Brazilian Journal of Genetics, 20, 651-653.

Selivon, D., Perondini, A. L. P., \& Morgante, J. S. (2005). A genetic-morphological characterization of two cryptic species of the Anastrepha fraterculus complex (Diptera, Tephritidae). Annals of the Entomological Society of America, 98, 367-38. https://doi.org/10.1603/0013-8746

Selivon, D., Vretos, C., Fontes, L., \& Perondini, A. L. P. (2004). New variant forms in the Anastrepha fraterculus complex. In B. Barnes (Ed.), Proc 6th International Fruit Flies Symposium (pp. 253-258). Isteg Scientific Publications, Irene.

Shearman, D. C., \& Frommer, M. (1998). The Bactrocera tryoni homologue of the Drosophila melanogaster sex-determination gene doublesex. Insect Molecular Biology, 7, 355-366. https://doi.org/10.1046/ j.1365-2583.1998.740355.x

Song, H., Zhang, J., Li, D., Cooper, A. M. W., Silver, K., Li, T., ... Zhang, J. (2017). A double-stranded RNA degrading enzyme reduces the efficiency of oral RNA interference in migratory locust. Insect Biochemistry and Molecular Biology, 86, 68-80. https://doi.org/10.1016/j.ibmb.2017.05.008

Telfer, W H. (2009). Egg formation in Lepidoptera. Journal of Insect Scince, 9, 50. https://doi.org/10.1673/ 031.009.5001

Vaníčková, L., Hernández-Ortiz, V., Joachin-Bravo, I. S., Dias, V., Roriz, A. K. P., Laumann, R. A., ... Nascimento, R. R. do. (2015). Current knowledge of the species complex Anastrepha fraterculus (Diptera, Tephritidae) in Brazil. Zookeys, 540, 211-237. https://doi.org/10.3897\%2Fzookeys.540.9791

Verhulst, E. C., van de Zande, L., \& Beukeboom, L. W. (2010). Insect sex determination: It evolves around transformer. Current Opinion in Genetics \& Development, 20, 376-383. https://doi.org/10.1016/j.gde. 2010.05.001

White, I. M., \& Elson-Harris, M. M. (1992). Fruit flies of economic significance: Their identification and bionomics. CAB International, Wallingford.

Willhoeft, U., \& Franz, G. (1996). Identification of the Sex-Determining Region of the Ceratitis capitata Y Chromosome by Deletion Mapping. Genetics, 144, 737-745. https://doi.org/10.1093/genetics/144.2.737

Yu, N., Christianens, O., Liu, J., Niu, J., Cappelle, K., Caccia, S., ... Smagghe, G. (2013). Delivery of dsRNA for RNAi in insects: An overview and future directions. Insect Science, 20, 4-14. https://doi.org/10.1111/ j.1744-7917.2012.01534.x

Yu, X. D., \& Killiny, N. (2017). Effect of parental RNA interference of a transformer-2 homologue on female reproduction and offspring sex determination in Asian citrus psyllid. Physiological Entomology, 43, 42-50. https://doi.org/10.1111/phen.12223

Zhang, H., Li, H. C., \& Miao, X. X. (2013). Feasibility, limitation and possible solutions of RNAi-based technology for insect pest control. Insect Science, 20, 15-30. https://doi.org/10.1111/j.1744-7917.2012. 01513.x

Zotti, M. J., \& Smagghe, G. (2015). RNAi technology for insect management and protection of beneficial insects from diseases: Lessons, challenges and risk assessments. Neotropical Entomology, 44, 197-213. https://doi.org/10.1007/s13744-015-0291-8

Zucchi, R. A., \& Moraes, R. C. B. (2008). Fruit flies in Brazil: Anastrepha species and their host plants and parasitoids. Retrieved August 10, 2018, from http://www.lea.esalq.usp.br/anastrepha 


\section{Copyrights}

Copyright for this article is retained by the author(s), with first publication rights granted to the journal.

This is an open-access article distributed under the terms and conditions of the Creative Commons Attribution license (http://creativecommons.org/licenses/by/4.0/). 